\title{
An Investigation on Mechanical and Microstructural Properties of Porous Nickel-Based Alloy Fabricated by Investment Casting as an Implant Materials
}

\author{
Yusuf $\operatorname{Er}^{*} \mathbb{D}$ \\ "Firat University, Department of Airframes and Powerplants, 23119, Elazig, Turkey. (e-mail: yusufer@ firat.edu.tr).
}

\section{ARTICLE INFO}

Received: Jul., 14. 2021

Revised: Sep., 22. 2021

Accepted: Sep., 25. 2021

Keywords:

Metal foams

Biomaterials

Mechanical properties

Investment casting

Nickel-Chrome-Molybdenum

Corresponding author: Yusuf Er

ISSN: $2536-5010$ | e-ISSN: 2536-5134

\section{ABSTRACT}

In this study, Nickel-Chrome-Molybdenum alloy is manufactured using investment casting method with centrifugal casting device from a polyurethane foam model in a regular and openpore form, as a hard tissue implant. The samples produced have 10, 20, and $30( \pm 3)$ pores per inch and $0.0008,0.0017$, and $0.0027 \mathrm{~g} / \mathrm{mm}^{3}$ densities, respectively.

Young's modulus, hardness and mechanical behaviors of the samples were investigated by SEM, EDS and compressive test.

As a result, it is seen that the pore size and the pore wire diameter of the samples could be controlled thus compression strength and young modulus. In this way it was understood that an implant material could be produced with similar mechanical properties to the human bone.

DOI: https://doi.org/10.36222/ejt.971029

\section{INTRODUCTION}

Lightweight cellular solids with stochastic cells can be manufactured from numerous metals and metal alloys by a wide variety of vapor, liquid and solid-state process [1]. The applications of metal foams are in a wide range of biomaterials, aircraft, impact energy absorbers, silencers, flame arresters, heaters, heat exchangers, constructional materials, etc. [2-7]. More than 20 years, fabrication methods for porous metals have been developed to imitate bone properties [8-16]. Many parameters on the porous implant should be taken into account to ensure biocompatibility, such as pore shape, pore size, porosity and high purity. Pore morphology, size and porosity are the determining factors. For this, a thorough understanding of fracture behavior is required for successful industrial application $[17,18]$. Furthermore, the hollow space created by these biomaterials' interconnected open-cellular microstructure enables for simple bodily fluid movement and, as a result, the formation of new bone tissues. The properties of these cellular materials depend upon the properties of base metal alloy, the relative density and the topology [19-21]. According to Curran, the material utilized for the manufacturing technique; the durability of the foams generated with metal powder and the powder metallurgy method was related to the smallest areas between the metal or granules. He observed that the specific endurance of foams generated by powder metallurgy would be poor due to their manufacturing process [7]. Yamada et al. stated that an open pore casting was realized utilizing the infiltration technique using a polyurethane foam model, and that the materials utilized for production were of excellent quality and dependable, with a porosity rate of up to $98 \%$. [22]. Yamada et al. further said that this process may be used to cast any alloy or metal. It is especially appealing because the strength and Young's modulus of the cellular materials may be changed by porosity modification to match the strength and Young's modulus of real bone. As a result, novel bonesubstitute materials with high strength and suitable Young's modulus are required to assure the biomechanical characteristics of natural bones [22]. According to researches, the average pore size of the porous bone replacement material implanted must have pore size in order for the bone tissue ingrowth to progress. This size should be between 200 to $500 \mu \mathrm{m}$. [20-24]. Nickel, Chromium and Molybdenum elements are in the class of metallic biomaterials $[25,26]$. These elements are frequently used in biomaterials studies [2634].

In this study, Ni-Cr-Mo alloy is manufactured using investment casting [21, 35, 36]. method from a polyurethane foam model in a regular and open-pore form, as a hard tissue implant. Young's modulus, hardness and mechanical behavior 
of the samples were investigated by SEM, EDS, and compressive test

\section{MATERIALS AND METHOD}

\subsection{Production of Samples}

The alloy which was used in this study is commercially produced by the Böhler Company. The mechanical properties of alloy are given in Table 1. In the production of the samples, two-stage casting method was used. In this method, the open pore metal foams are produced by using polyurethane foams. Polyurethane foams with open pores in three different sizes were used as a sample model.

TABLE 1

THE MECHANICAL PROPERTIES OF ALLOY

\begin{tabular}{|l|l|}
\hline Density & $8.8 \mathrm{~g} / \mathrm{cm}^{3}$ \\
\hline Vickers hardness & $195 \mathrm{HV}$ \\
\hline Young modulus & $215 \mathrm{GPa}$ \\
\hline Melting temperature & $1280-1350^{\circ} \mathrm{C}$ \\
\hline Casting temperature & $1410^{\circ} \mathrm{C}$ \\
\hline
\end{tabular}
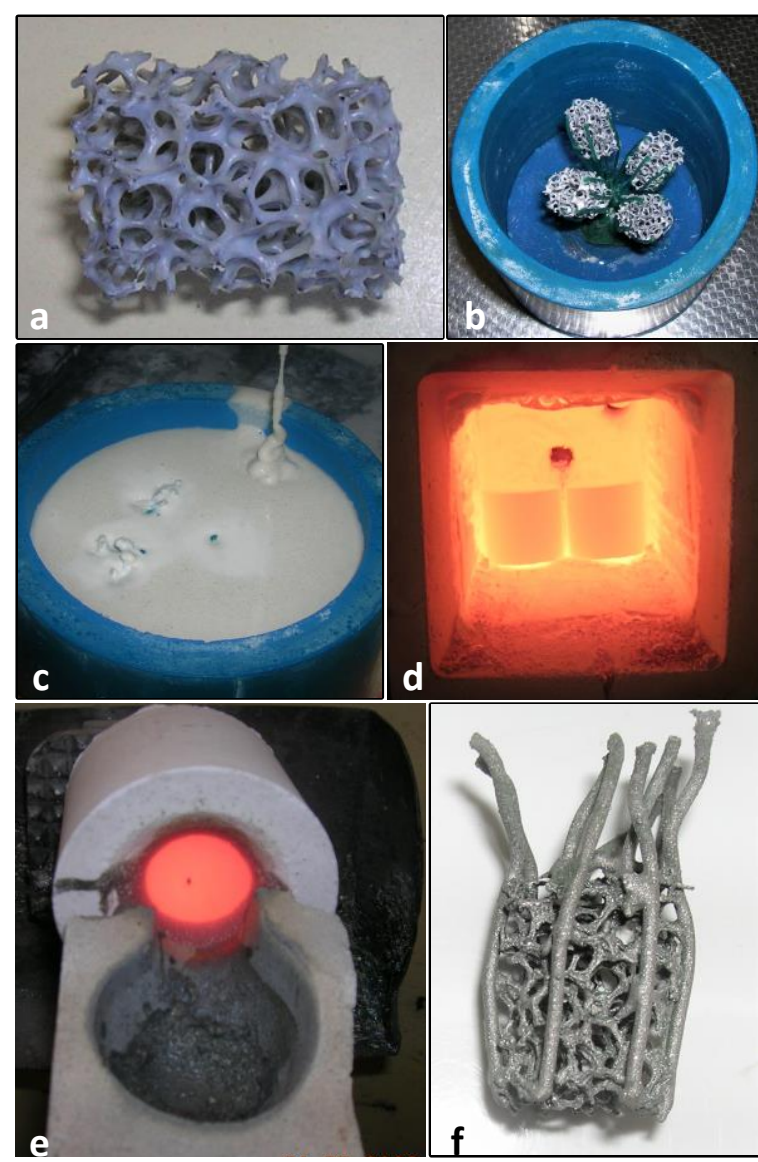

Figures 1. a, b, c, d, e, f Production stages of samples

The sample models created had 10, 20, and $30( \pm 3)$ pores per inch (ppi) and densities of $0.0008,0.0017$, and $0.0027 \mathrm{~g} / \mathrm{mm}^{3}$, respectively (Fig. 1. a). Then the mold tree was created and placed in the mold chamber (Fig. 1. b). Precision casting plaster was poured into the mold cavities to create the molds (Fig. 1. c). For the preparation of precast, prepared molds were heated for 1 hour at $1000^{\circ} \mathrm{C}$ in a thermocouple equipped oven (Fig. 1 . d). In this manner, the cast chamber in the mold was formed by burning away polyurethane foams. The alloy is then heated to $1410^{\circ} \mathrm{C}$ before being put into molds using a centrifugal casting process (Fig. 1. e). Molds were allowed to cool before being broken and cleaned to remove the casing. A sufficient number of samples were produced in this way (Fig. 1. f). Figures 1. shows the production stages.

\subsection{Density Measurement}

The mass and volume relationship was used to calculate the densities of the samples with different pore sizes. Formula (1) was used to determine the densities of solid metal $\left(\rho_{\text {Bulk }}\right)$ and porous metal ( $\left.\rho_{\text {Porous }}\right)$ samples. Then, using these density values obtained from each sample, the $\%$ porosity amounts ( $\varepsilon$ ) were determined with the formula (2) [37].

$$
\begin{aligned}
& \rho=\frac{m}{v} \\
& \rho: \text { Density, }\left(\mathrm{g} / \mathrm{mm}^{3}\right) \\
& m: \text { Mass, } \mathrm{g} \\
& v: \text { Volume, } \mathrm{mm}^{3} \\
& \varepsilon=\left(1-\frac{\rho_{\text {Porous }}}{\rho_{\text {Bulk }}}\right) x 100
\end{aligned}
$$

$$
\varepsilon: \% \text { porosity amounts }
$$

\subsection{Metallographic Examination}

Porous samples which obtained from Ni-Mo-Cr alloys were prepared metallographically to examine the microstructure. The samples were abraded with 220, 400, 600, 800, 1200 mesh sandpaper, respectively. It was then polished with a 3 micron polycrystalline diamond paste using a broadcloth. As the etching process, firstly, $95 \mathrm{ml}$ of water, $5 \mathrm{ml}$ of $\mathrm{HCl}$ solution was kept in an electrolytic etching agent with 5-10 V and DC current for three minutes to release molybdenum. Then, the etching process was completed by immersing the sample in the chemical etching (5ml HNO3, $200 \mathrm{ml} \mathrm{HCl}, 65 \mathrm{~g} \mathrm{FeCl} 2$ ) for a few seconds. The microstructure characterization of the produced samples was examined under the LEO brand scanning electron microscope.

\subsection{Mechanic Examination}

Compression tests were performed on an Instron 8500 universal type tension-compression machine. For the compression experiments, a total of 9 compression samples, three from each of the three samples with different pore sizes were prepared. The dimensions of the samples prepared for the compression test were prepared according to the TS 6936 standard and at room temperature, different from the dimensions of the sample to be used as an implant.

\section{RESULTS and DISCUSSION}

\subsection{Determination of Pore Ratio}

The densities of the produced samples were calculated with the formulas specified in section 2.2. The densities of three samples for each sample group were calculated and the average values were found. Pore sizes were determined by the number of ppi. The exact density of the alloy material used in the casting and the pore ratio of the produced samples are given in 
Table 2 by determining the relative densities as well as the \% porosity amounts.

TABLE 2

DENSITIES AND POROSITIES VALUES

\begin{tabular}{|c|c|c|c|c|}
\hline $\begin{array}{c}\text { Sample } \\
\text { Group }\end{array}$ & $\begin{array}{c}\text { Bulk } \\
\text { densities } \\
\left(\mathrm{g} / \mathrm{mm}^{3}\right) \\
\left(\rho_{\text {Bulk }}\right)\end{array}$ & $\begin{array}{c}\text { Pore sizes } \\
(\mathrm{ppi})\end{array}$ & $\begin{array}{c}\text { Porous } \\
\text { densities } \\
\left(\mathrm{g} / \mathrm{mm}^{3}\right) \\
\left(\rho_{\text {Porous }}\right)\end{array}$ & $\begin{array}{c}\text { General } \\
\text { porosities } \\
\text { in percent } \\
(\varepsilon)(\%)\end{array}$ \\
\hline A & 0,0088 & $10 \pm 3$ & 0,0008 & 90,7 \\
\hline B & 0,0088 & $20 \pm 3$ & 0,0017 & 81,0 \\
\hline C & 0,0088 & $30 \pm 3$ & 0,0027 & 68,8 \\
\hline
\end{tabular}

When the values in the table are examined; The fact that the percentage of porosity $(\%)$ of all three samples does not change regularly depending on the pore ratios may be related to the fact that the fiber sections are not the same. Yamada and his friends [22], used $\mathrm{Al}$ and $\mathrm{Mg}$ materials, for $\mathrm{Al}$ in the samples obtained by polyurethane foam model and infiltration method; For $\mathrm{Mg}$ between $0.0471 \mathrm{gr} / \mathrm{mm}^{3}$ and $0.0653 \mathrm{gr} / \mathrm{mm}^{3}$; Relative density values in the range of $0.028 \mathrm{gr} / \mathrm{mm}^{3}$ and $0.030 \mathrm{gr} / \mathrm{mm}^{3}$ were obtained. In this study; Unlike Yamada's study [22], centrifugal casting device was used instead of infiltration casting. For NiCr-Mo $\left(0.0088 \mathrm{gr} / \mathrm{mm}^{3}\right)$ alloy, which is a denser metal; Relative density values were obtained in the range of 0.0008 $\mathrm{gr} / \mathrm{mm}^{3}$ to $0.0027 \mathrm{gr} / \mathrm{mm}^{3}$.

\subsection{Metallographic Test Results}

For SEM investigations, the produced samples were divided into three groups: group A, group B, and group C based on their pore diameters. SEM examinations and EDS analyzes of groups A, B and C are given, respectively.

EDS analyses were taken from three different regions shown with ellipses in the figure to determine the elemental amounts of group A samples. According to the EDS results received; When the results of the region marked as ellipse 0 on the black islet in the matrix are examined, it is observed that the percentages of molybdenum and silicon elements increase, they become poorer in nickel, and there is no significant change in the chromium ratio (Figures 2). It is seen that the alloy content of the region shown as ellipse 0 consists of $39.82 \% \mathrm{Ni}$, $23.52 \% \mathrm{Mo}, 26.30 \% \mathrm{Cr}$ and $10.35 \% \mathrm{Si}$ elements. When the EDS analyses of the region marked with ellipse1 in the matrix adjacent to the islet on the same photograph were examined, it was observed that there was no enrichment in the nickel ratio, no depletion in the molybdenum and silicon ratios, and no significant change in the chromium ratio. When the alloy content of the region shown as Ellipse 1 is examined, it is seen that it consists of $60.98 \% \mathrm{Ni}, 28 \% \mathrm{Mo}, 7.67 \%$ and $3.36 \% \mathrm{Si}$ elements. When the EDS analysis of the point shown as ellipse2 in the SEM photograph taken on the matrix is examined, it is seen that the matrix consists of $64.39 \% \mathrm{Ni}$, $27.62 \% \mathrm{Cr}, 5.87 \%$ Mo and $2.1 \%$ Si elements.

EDS analyses were taken from two different regions shown with ellipses in Figure 3 to determine the element ratios of the $\mathrm{B}$ group samples. According to the EDS results received; When the results of the region marked as ellipse 0 on the black islet in the matrix are examined, it is observed that the percentages of molybdenum and silicon elements increase, they become poorer in nickel, and there is no significant change in the chromium ratio. It is seen that the alloy content of the region shown as ellipse 0 consists of $46.18 \% \mathrm{Ni}, 24.81 \% \mathrm{Cr}, 19.93 \%$ Mo and $9.08 \%$ Si elements. When the EDS analyzes of the region marked with ellipse 1 in the matrix adjacent to the islet on the same photograph were examined, it was observed that there was no significant change in the nickel ratio, enrichment in the molybdenum and silicon ratios, and no significant change in the chromium ratio.

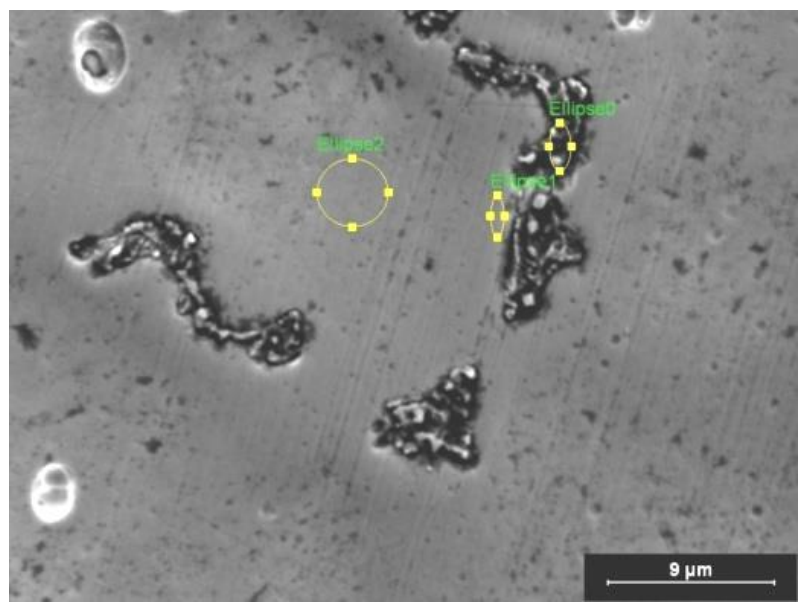

Figures 2. SEM image and EDS analysis regions of group A sample

When the alloy content of the region shown as Ellipse 1 is examined, it is seen that it consists of $63.54 \% \mathrm{Ni}, 27.39 \% \mathrm{Mo}$, $6.42 \%$ and $2.65 \%$ Si elements.

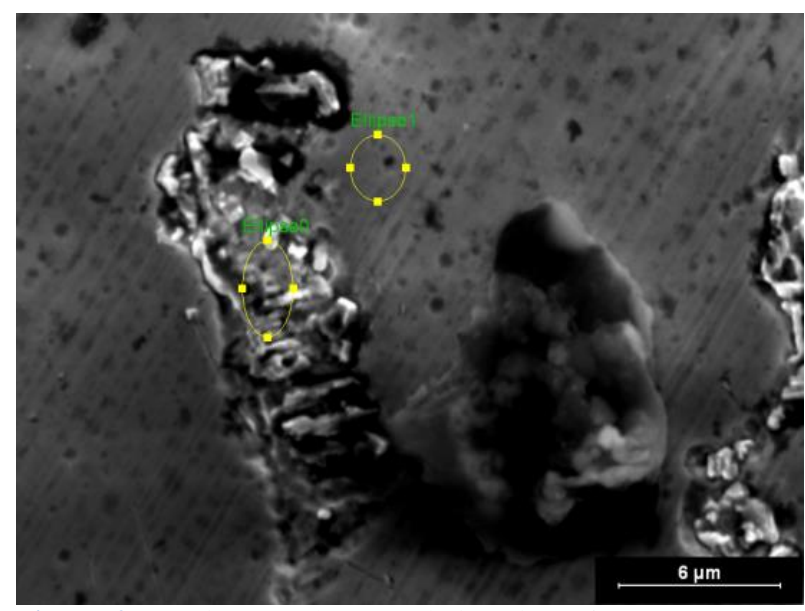

Figures 3. SEM image and EDS analysis regions of group B sample

In order to determine the element ratios of the $\mathrm{C}$ group samples, EDS analyses were taken from the region indicated by ellipse 0 in Figure 4 . When the EDS analysis of the point taken on the matrix and indicated by the ellipse 0 is examined, it is seen that the matrix consists of $66.35 \% \mathrm{Ni}, 26.34 \% \mathrm{Cr}$, $5.43 \%$ Mo and $1.89 \%$ Si elements. The results obtained in the examination and analysis were found to be very close to each other. According to the results obtained from the EDS analysis, it was concluded that the pore sizes did not affect the microstructure.

Figure 5 shows the microstructure photograph of the sample taken with an optical microscope. The photograph shows three separate solidification structures. The region numbered 1 is primary solidified, the region numbered 2 is secondary solidified and the region numbered 3 represents the interdendritic region. As can be seen from the microstructure photographs, the alloy exhibited a dendritic structure. When we look at the EDS values in general; While the matrix of the sample is predominantly $\mathrm{Ni}-\mathrm{Cr}$, it is understood that $\mathrm{Mo}$ and $\mathrm{Si}$ 
precipitate in the matrix and form islets with a homogeneous distribution.

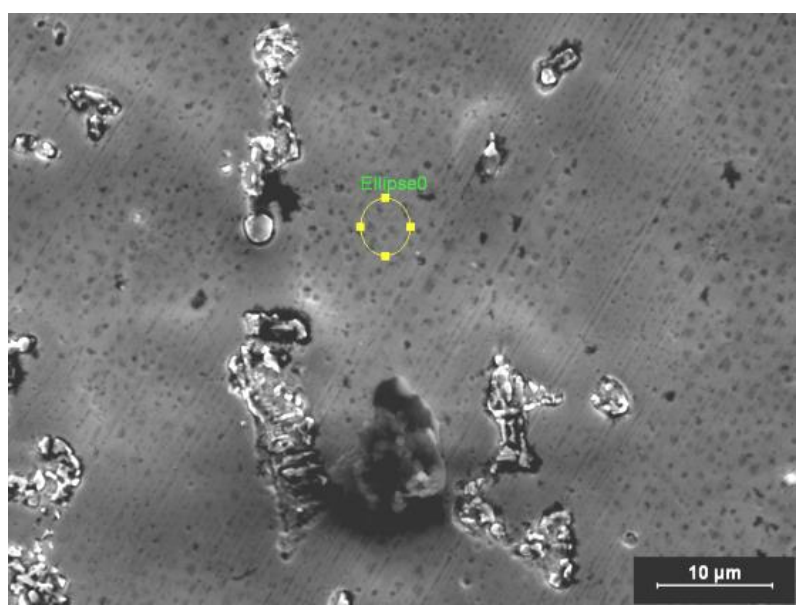

Figures 4. SEM image and EDS analysis regions of group C sample

Christopher et al.; In their study, they produced a $62.2 \% \mathrm{Ni}$, $25 \% \mathrm{Cr}, 9.5 \%$ Mo and 3.3\% Si doped alloy named Matchmate as casting and defined the obtained microstructure as dendritic [38]. Study by Christopher et al. and the microstructure obtained in this study confirm each other.

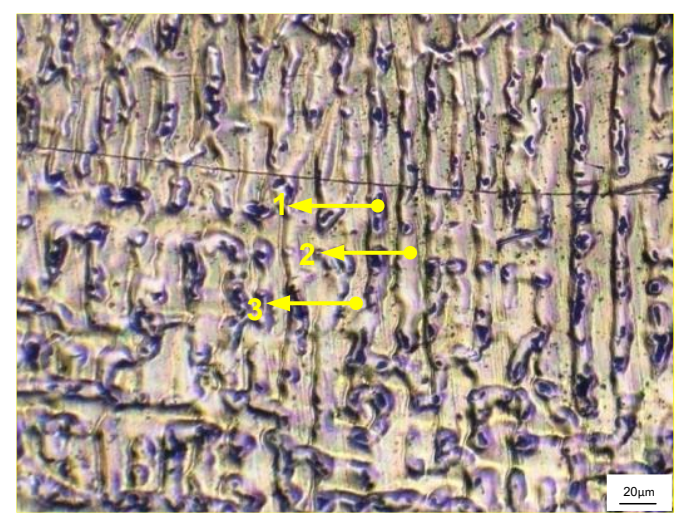

Figures 5. Optical microscope image of sample

\subsection{Compression Test Results}

When the comparative stress-strain diagrams of the A, B and $\mathrm{C}$ group samples in Figure 6 are examined, it can be observed that pore ratios and filament diameters have an influence on modulus of elasticity. Stretching is found to grow in direct proportion to rising pore ratios. However, although the pore ratio of group B samples is higher than that of group A samples, the reason why the stress values of group A samples are higher can be attributed to the thicker cross-section of the filament diameters. When the diagram of the $\mathrm{C}$ group samples is examined, it is seen that the stress values rise based on both the pore ratio and the fiber section. This result is important in that it shows that the desired stress values can be controlled depending on the pore sizes and fiber cross sections. In their study Tuncer and Arslan determined that the plateau region becomes more ambiguous as the relative density increases in the stress diagram, they obtained from titanium foam with different levels of porosity, produced by space holder method [15]. Similarly, the smooth character of the curves in the diagram obtained in this study confirms that the ductile behavior of foams in the porosity range studied. (Figure 6)

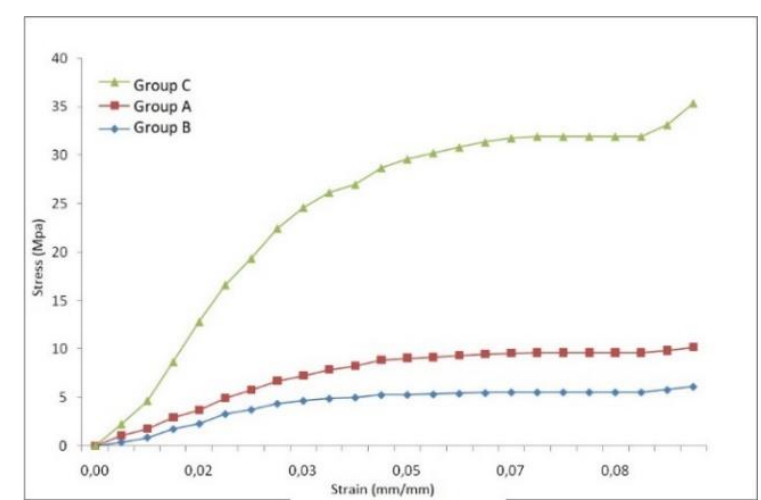

Figures 6. Comparative stress-strain diagrams of A, B and C group samples

\section{CONCLUSION}

In this study, it was investigated Ni-based Ni-Cr-Mo alloy, which is widely used in orthopedics and dentistry, can be produced in an open pore structure by precision casting method and the controllability of pore size and filament thicknesses.

- It has been observed that a material with a Ni-Cr-Mo alloy can be successfully produced in its final shape in a centrifugal casting device with an open pore structure and a density range of $66.8 \%$ to $91.5 \%$, without the need for a second process, by precision casting method.

- In the centrifugal casting device, the pore sizes and controllability of the fiber sections of the samples produced by the investment casting method are shown.

- As a result of the microstructure examinations on the sample as a result of the casting process, it was observed that the alloy exhibited a dendritic structure. While the matrix of the sample is predominantly $\mathrm{Ni}-\mathrm{Cr}$, it is understood that Mo and Si precipitate in the matrix and form islets with a homogeneous distribution.

- When the density values of the samples were examined, it was seen that the relative density was related to the increased pore size and filament cross section.

- As a result of the compression tests applied to the porous samples; It was seen that pore size and filament thicknesses play an important role in determining the modulus of elasticity. Accordingly, the sample with the smallest pore and relatively thick fiber section showed the highest modulus of elasticity, while the sample with the thinnest fiber section and relatively large pore size showed the lowest modulus of elasticity.

\section{ACKNOWLEDGEMENT}

The author acknowledges the Scientific Research Foundation, Firat University (FUBAP-Project no: 1018) for their financial support. I remember with respect Prof. Dr. Nuri Orhan who contributed technically to this study.

\section{REFERENCES}

[1] Queheillalt, Douglas T., Yasushi Katsumura, Haydn NG Wadley, "Synthesis of stochastic open cell Ni-based foams", Scripta Materialia 50.3 (2004): 313-317

[2] Kılıç M., "Toz metalurjisi ile Üretilen NiTi Alaşımına Al'un Etkisi". Bitlis Eren Üniversitesi Fen Bilimleri Dergisi. 2021; 10(1): 256-267. 
[3] V. Koç, V. V. Çay, "Investigation of Wear Behavior of Ti6AL4V/B4C Composites Produced by Powder Metallurgy", European Journal of Technique (EJT) 10.2 (2020): 444-453.

[4] M. F. Ashby, A. Evans, N. A. Fleck, L. J. Gibson, J. W. Hutchinson, H. N. G. Wadley: "Metal Foams: A Design Guide", Butterworth Heinemann, Boston, USA (2000)

[5] J. Banhart: "Manufacture, characterization and application of cellular metals and metal foams", Progress in Materials Science 46 (2001), pp. 559-562

[6] B. Jiang, N. Q. Zhao, C. S. Shi, J. J. Li: "Processing of open-cell aluminum foams with tailored porous morphology", Scripta Materialia 53 (2005), pp. 781-785

[7] D. Curran, "Metal Foams", Cambridge University Press, Cambridge, UK, 2001

[8] Mour M, Das D, Winkler T, Hoenig E, Mielke G, Morlock MM, Schilling AF., "Advances in Porous Biomaterials for Dental and Orthopedic Applications", Materials, 2010; 3(5):2947-2974.

[9] D. C. Dunand, "Processing of Titanium Foams", Advanced Engineering Materials, 2004; 6(6), pp. 369-376.

[10] V. Karageorgiou, D. Kaplan, "Porosity of 3D biomaterial scaffolds and osteogenesis", Biomaterials, Volume 26, Issue 27, 2005, pp 5474-5491,

[11] M. A. Lopez-Heredia, J. Sohier, C. Gaillard, S. Quillard, M. Dorget, P. Layrolle, "Rapid prototyped porous titanium coated with calcium phosphate as a scaffold for bone tissue engineering", Biomaterials, Volume 29, Issue 17, 2008, pp 2608-2615,

[12] G. E. Ryan, A. S. Pandit, D. P. Apatsidis, "Porous titanium scaffolds fabricated using a rapid prototyping and powder metallurgy technique", Biomaterials, Volume 29, Issue 27, 2008, pp 3625-3635,

[13] V. K. Balla, S. Bodhak, S. Bose, A. Bandyopadhyay, "Porous tantalum structures for bone implants: Fabrication, mechanical and in vitro biological properties", Acta Biomaterialia, Volume 6, Issue 8, 2010, pp 3349-3359,

[14] T.F. Hong, Z.X. Guo, R. Yang, "Fabrication of porous titanium scaffold materials by a fugitive filler method". Journal of Materials Science: Materials in Medicine, 19, 3489 (2008).

[15] N. Tuncer, G. Arslan, "Designing compressive properties of titanium foams". Journal of Materials Science, 44, pp 1477-1484 (2009).

[16] J. P. Li, S. H. Li, C. A. V. Blitterswijk, K. de Groot, "A novel porous Ti6Al4V: Characterization and cell attachment", Journal of Biomedical Materials Research, 73A(2), 2005, pp 223-233,

[17] C.E Wen, M Mabuchi, Y Yamada, K Shimojima, Y Chino, T Asahina, "Processing of biocompatible porous Ti and Mg", Scripta Materialia, Volume 45, Issue 10, 2001, Pages 1147-1153,

[18] M. S. Aly, "Effect of pore size on the tensile behavior of open-cell Ti foams: Experimental results", Materials Letters, Volume 64, Issue 8, 2010, Pages 935-937,

[19] L. D. Zardiackas, D. E. Parsell, L. D. Dillon, D. W. Mitchell, L. A. Nunnery, R. Poggie, "Structure, metallurgy, and mechanical properties of a porous tantalum foam", Journal of Biomedical Materials Research, Volume58, Issue2, 2001, pp 180-187,

[20] A. J. T. Clemow, A. M. Weinstein, J. J. Klawitter, J. Koeneman, J. Anderson, "Interface mechanics of porous titanium implants", Journal of Biomedical Materials Research, Volume15, Issue1, 1981, pp 73-82,

[21] Y. Er, E. Ünsald1, "The Production of Nickel-Chromium-Molybdenum Alloy with Open Pore Structure as an Implant and the Investigation of Its Biocompatibility in Vivo", Advances in Materials Science and Engineering, vol. 2013, Article ID 568479, 7 pages, 2013.

[22] Y. Yamada, K. Shimojima, Y. Sakaguchi, "Effects of heat treatment on compressive properties of AZ91 Mg and SG91A Al foams with opencell structure," Materials Science and Engineering A, vol. 280, no. 1, pp. 225-228, 2000

[23] C. E. Wen, M. Mabuchi, Y. Yamada, K. Shimojima, Y. Chino, and T. Asahina, "Processing of biocompatible porous $\mathrm{Ti}$ and Mg," Scripta Materialia, vol. 45, no. 10, pp. 1147-1153, 2001.

[24] E. Tsuruga, H. Takita, H. Itoh, Y. Wakisaka, Y. Kuboki, "Pore size of porous hydroxyapatite as the cell-substratum controls BMP-induced osteogenesis", Journal of Biochemistry, vol. 121, no. 2, pp. 317-324, 1997.

[25] Kilic, M., Kirik, I., Okumuş, M., "Microstructure examination of functionally graded $\mathrm{NiTi} / \mathrm{NiAl} / \mathrm{Ni} 3 \mathrm{Al}$ intermetallic compound produced by self-propagating high-temperature synthesis", Kovove Materialy. 55 . 97-106. 10.4149/km-2017-2-97.

[26] H. Nishikawa, N. Maruyama, "Mechanical testing of metallic biomaterials", Metals for Biomedical Devices (Second Edition), 2019, pp 189-211,

[27] A. Glied, J. Mundiya, "Implant Material Sciences", Dental Clinics of North America, Volume 65, Issue 1, 2021, pp 81-88,
[28] N. H. Mat-Baharin, M. Razali, S. Mohd-Said, J. Syarif, A. Muchtar, "Influence of alloying elements on cellular response and in-vitro corrosion behavior of titanium-molybdenum-chromium alloys for implant materials", Journal of Prosthodontic Research, Volume 64, Issue 4, 2020, pp 490-497,

[29] S. Terpilowska, "Chapter 11 - Pro- and antioxidant activity of chromium(III), iron(III), molybdenum(III), or nickel(II)", Toxicology, Academic Press, 2021, pp 99-106,

[30] D. Mehrotra, S. Kumar, P. Mehrotra, R. Khanna, V. Khanna, D. Eggbeer, P. Evans, "Patient specific total temporomandibular joint reconstruction: A review of biomaterial, designs, fabrication and outcomes", Journal of Oral Biology and Craniofacial Research, Volume 11, Issue 2, 2021, pp 334-343,

[31] P. A. B. Kuroda, M. A. R. Buzalaf, C. R. Grandini, "Effect of molybdenum on structure, microstructure and mechanical properties of biomedical Ti-20Zr-Mo alloys", Materials Science and Engineering: C, Volume 67, 2016, pp 511-515,

[32] N. Ranjan, "A Bibliometric Analysis and Visualisation of Research Trends in Health Issues of Nickel-Implants", Turkish Journal of Computer and Mathematics Education, Vol. 12 No. 2 (2021), pp 109114

[33] G. Thind, "A Bibliometric Analysis and Visualisation of Research Trends in Toxicity of Nickel-implants", Turkish Journal of Computer and Mathematics Education, Vol.12 No.2 (2021), pp 75 -80,

[34] V. V. Çay, S. Ozan, "Superalloys and Application Areas." Doğu Anadolu Bölgesi Araştırmaları, (2005).

[35] S. Pattnaik, D. B. Karunakar, P.K. Jha, "Developments in investment casting process-A review", Journal of Materials Processing Technology, Volume 212, Issue 11, 2012, pp 2332-2348,

[36] J. Banhart, J. Baumeister, "Production Methods for Metallic Foams", MRS Proceedings, (1998). 521, 121.

[37] B. Y. Li, L. J. Rong, Y. Y. Li, and V. E. Gjunter, "Synthesis of porous $\mathrm{Ni}$-Ti shape-memory alloys by self-propagating high temperature synthesis: reaction mechanism and anisotropy in pore structure", Acta Materialia, vol. 48, no. 15, pp. 3895-3904, 2000.

[38] M. W. Christopher, M. S. Richard, J. P. F. Garry, and J. D. Alison, "Dental materials," Dental, vol. 982, p. 10, 2006.

\section{BIOGRAPHIE}

Yusuf Er born in Batman in 1966, achieved his MSc and his $\mathrm{PhD}$ at the University of Firat, Elazig, Turkey, in 2002 and 2008, respectively, while working in the Ministry of Education, Gazi Vocational High School. At present, he is employed at the School of Aviation, University of Firat. His fields of interests include investment casting, porous materials, aircraft materials, composite materials, manufacturing techniques and wear. 